The Council had adjourned for dinner from 6:30 P.M. until 8:00 P.M. and finally adjourned after midnight.

Bethelehem, Pennsylvania

Everett Pitcher Secretary

Middletown, Connecticut

WALTER H. GoTTSCHALK

Associate Secretary

\title{
THE APRIL MEETING IN RENO
}

The seven hundred thirty-fifth meeting of the American Mathematical Society was held at the University of Nevada in Reno, Nevada, on Friday and Saturday, April 23 and 24, 1976. There were 162 registrants, including 126 members of the Society.

By invitation of the Committee to Select Hour Speakers for Far Western Sectional Meetings, there was one invited hour address. Professor Robert T. Powers of the University of Pennsylvania and the University of California, Berkeley, lectured on KMS states of UHF algebras and their application to quantum statistical mechanics. He was introduced by Professor Theodore W. Palmer.

There were four special sessions. Professor Bruce E. Blackadar of the University of Nevada, Reno, organized a Special Session on $C^{*}$-Algebras and Related Topics. The speakers were Bruce A. Barnes, Bruce E. Blackadar, Lawrence G. Brown, Man-Duen Choi, John A. Ernest, Jacob Feldman, Ramesh A. Gangolli, Philip P. Green III, Peter Florin Hahn, J. William Helton, Calvin C. Moore, Marc A. Rieffel, Jonathan Rosenberg, and William M. Scruggs. Professor Peter A. Griffin of California State University, Sacramento, organized a Special Session of thirty-minute talks on Mathematics of Gambling. The speakers were Thomas M. Cover, William H. Cutler, Thomas S. Ferguson, and Peter A. Griffin. Professor Darrell C. Kent of Washington State University organized a Special Session on Convergence Spaces. The contributors were Thomas K. Boehme, Allan C. Cochran, William Alan Feldman, Roman Frič, Ray J. Gazik, James M. Irwin, Darrell C. Kent, Terrence S. McDermott, James F. Porter, Ellen E. Reed, Gary D. Richardson, M. Schroder, and Edwin F. Wagner. The proceedings of these sessions on Convergence Spaces will be published by the University of Nevada. Professor Ralph N. McKenzie of the University of California, Berkeley, organized a Special Session on Varieties of Algebras. The speakers were Kirby A. Baker, John T. Baldwin, George M. Bergman, Alan Day, R. P. Dilworth, George A. Grätzer, Bjarni Jonsson, Peter H. Krauss, George McNulty, Philip Olin, A. Regev, Walter F. Taylor, and Paul M. Weichsel.

There were three sessions of contributed papers. They were chaired by Robert D. Davis, Robert Clark Hooper, and Edward F. Wishart.

The meeting was held in conjunction with a meeting of the Association for Symbolic Logic. The Association scheduled two one-hour talks. Professor Gabriel Sabbagh of the University of Paris VII and the University of California, Berkeley, lectured on First order properties of linear groups and Professor Yiannis N. Moschovakis of the University of California, Los 
Angeles, gave a survey lecture entitled Inductive definability. The Association also scheduled four invited one-half hour talks as follows: Michael Beeson of Stanford University spoke on The principle of local continuity, John S. Schlipf of the California Institute of Technology lectured on Ordinal spectra of first order theories, Andreas R. Blass of the University of Michigan lectured on Ultraproduct proofs of ultrafilter theorems, and Richard J. Laver of the University of Colorado spoke on Strong saturation properties of ideals.

The local arrangements committee consisted of Trevor J. McMinn (chairman), Bruce Blackadar, Robert Clark Hooper, and Edwin F. Wagner.

EUGENe, OREGON

Kenneth A. Ross Associate Secretary

\section{THE JUNE MEETING IN PORTLAND}

The seven hundred thirty-sixth meeting of the American Mathematical Society was held at Portland, Oregon, on Friday, June 18, 1976. The Mathematical Association of America and the Society for Industrial and Applied Mathematics held Northwest Sectional Meetings in conjunction with this meeting of the Society. All of their sessions were held on Saturday, June 19. In addition, $\mathrm{Pi} \mathrm{Mu}$ Epsilon sponsored a session of fifteen minute papers on Friday afternoon. A total of 136 people registered at the meeting, including 78 members of the Society.

The featured SIAM lecturer was Professor Philip M. Anselone of Oregon State University; he lectured on Nonlinear operator approximation theory and applications to integral equations. The MAA featured two invited hour addresses. Professor Richard M. Koch of the University of Oregon lectured on Invariant functions on matrices, and Professor Raymond Mayer of Reed College gave a lecture entitled Some applications of nonstandard analysis to number theory.

By invitation of the Committee to Select Hour Speakers for Far Western Sectional Meetings, there were two invited addresses. Professor R. James Milgram of Stanford University lectured on Generalized cohomology theories and their applications. He was introduced by Professor Lewis E. Ward, Jr. Professor Thomas M. Liggett of the University of California, Los Angeles, gave the second lecture. The title of his talk was The stochastic evolution of infinite systems of interacting particles. Professor Robert T. Smythe introduced Professor Liggett.

There were three sessions of contributed papers, chaired by Professors Gavin Bjork, Richard Iltis, and Joseph B. Roberts. Local arrangements were handled by Professor J. Richard Byrne.

Eugene, Oregon

KenNeth A. Ross Associate Secretary 